\title{
Empower English Teachers With Corpus in EFL Classroom
}

\author{
Xiuwen Wang ${ }^{1}$, Changiiang Liu ${ }^{1}$, Yanan Wang ${ }^{1}$ \\ ${ }^{1}$ Foreign Languages School, Nanjing University of Aeronautics and Astronautics, Nanjing, China. \\ Correspondence: Xiuwen Wang, 1012 Letter Box, Jiangjun Road Campus, Foreign Languages School, Nanjing \\ University of Aeronautics and Astronautics, Nanjing, P.R.China. 211106.
}

Received: March 13, 2018

doi:10.11114/ijce.v1i1.3202

\author{
Accepted: April 7, $2018 \quad$ Online Published: April 1, 2018 \\ URL: https://doi.org/10.11114/ijce.v1i1.3202
}

\begin{abstract}
English teachers in EFL classroom are faced with the following situations like rapid development of technology and network, together with the changing ideas of teaching and learning, more quick and critical students as well. Corpus and concordances can provide them with feasibility and possibility for mobile, experienced teaching and learning. This paper attempts to give some hints on the methods and strategies of teaching via corpus and concordances, upon which a model for teaching and learning is proposed.
\end{abstract}

Keywords: EFL classroom, corpus, concordances

\section{Introduction}

As is known to all, our world and society is changing at an ever increasing speed. With the development of technology and network, the whole world has become a global village that is closely connected with each other, whatever happens in some corner of the world will be known instantly by someone else in the far distance of another corner of the world. Teaching and learning can be carried out anytime and anywhere via mobile terminals. Students in EFL classroom are no longer the students ten or twenty years ago, instead, they are more critical learners, well informed and have access to the whole world. Hence, teachers in EFL classroom are faced with great challenges under this kind of rapid developing technology and society, let alone demanding students. However, teachers in EFL classroom are also enabled with enormous opportunities and possibilities. This paper will empower teachers in EFL classroom with one aspect of modern technology and network, i.e. corpus and concordances, and will propose some hints on what to do and how to do concerning teaching and learning via corpus and concordances so as to help teachers to adapt to modern teaching and learning.

\section{Method}

Methodology applied in this paper is qualitative analysis and induction and deduction. This paper is based on analyzing the problems shown in the present EFL classroom and then trying to provide strategies via corpus and concordance for English teaching and learning.

\section{Characteristics of Current Teaching and Learning}

\subsection{Characteristics of Effective and Efficient EFL Classroom}

Highly effective teaching and learning should create a safe learning environment supported by the teacher in which high, clear expectations are made, and positive relationships are fostered between the teacher and students, and more importantly, active learning should be promoted. In order to achieve a highly effective EFL classroom, the teachers are supposed to do the following:

1) create learning environments where under teachers' guidance, students are active participants both as individuals and as collaborative group members;

2) motivate students, arouse their curiosity, and nurture their desire for self-study;

3) cultivate cross cultural understandings and acceptance since learning a foreign language to some extent is to learn its culture;

4) encourage students to take responsibility for their own learning and accommodate to students' diverse learning needs;

5) display classroom management with high effectiveness and efficiency; 
6) provide students available access to technology and tools, in other words, teachers should be smart to utilize the modern teaching facilities;

7) design lessons that allow students to participate in activities in which they understand that learning is a process rather than cramming of knowledge.

While in many EFL classrooms, teachers fail to do so and students cannot actively participate in classroom or be authentically engaged in using modern technology in a safe, responsible and ethical way.

\subsection{Characteristics of Talents Cultivating of the New Century}

The teaching concept advocates that communicative competence is needed in talents cultivating of the new century, so does college English teaching, whose teaching goal is to foster students' English application ability, cross-cultural communicative consciousness and capability. In the meantime, college students also should develop their autonomous learning ability. Only by doing this can students use English effectively during study, work and social interaction in the future to meet both individual and social developmental requirements. The 21 st Century Skills announced by the American Council for Teachers of Foreign Language (ACTFL) include the following parts: information, media and technology skills for communication, collaboration, critical thinking and problem solving, etc.; life and career skills for flexibility, adaptability, initiative and self-direction, social and cross cultural skills, etc. These skills are also perfectly in line with the communicative competence firstly put forward by Hymes (1972), and later further developed by American linguist Bachman (1990). In information technology era, Lotherington and Ronda (2014) put forward a new concept of communicative competence which covers the following inspiring and essential aspects, such as the multimedia competency advocating the ability to navigate multiple digital platforms, and utilize multiple modalities for meaning making, and so on.

\subsection{Technology, Information and EFL Classroom}

In a word, there is a need to make some changes to the EFL classroom. Thanks to modern science and technology, people tend to lean on technology products during study, work and living, which gives rise to the convenient, mobile and experienced learning model. Since the Internet provides us large amount of data upon which we can experience corpus-based learning and teaching. This kind of teaching and learning strategy shows outstanding merits that students can foster those kinds of abilities mentioned above, and enhance EFL classroom effectiveness and efficiency.

\section{Availability of Corpus and Concordance}

Technology and network provide feasibility and possibility for mobile, experienced learning. This paper takes corpus and concordance as an example.

\subsection{What Is Corpus and Concordance?}

According to Flowerdew (1996), a corpus (pl. corpora) is a collection of language samples, written and/or spoken, processed on computer using one or more software tools for the purpose of analyzing the language itself for word use/usage and frequency and mainly for linguistic and dictionary use.

With the rapid development and wide use of computer technologies, corpora on the basis of computer technologies have become more and more widely acknowledged and applied into some areas, especially in the language teaching and learning it is a powerful tool. Thanks to a lot of great researchers, scholars, and research organizations around the world, various kinds of corpora, small or large scaled, personal or public, written or spoken, have been set up and available for us. Students of English in non-English speaking environment (e.g. EFL classroom) have a considerable amount of real English to explore and exploit. As for the large-scaled English corpora, there are some popular ones such as BNC (the British National Corpus), ANC (the American National Corpus), COCA (the Corpus of Contemporary American English), etc., of which this paper will search BNC since it is not only rich in natural and authentic English language data but also powerful in functions (Guy Aston, 1998).

A concordancer is a relatively simple piece of computer software which allows for a constructive search of large amount of texts for examples of a particular word or phrase, such as Monoconc/pro, Wordsmith, AntConc, ParaConc, etc. While a concordance is the outcome of a concordancer usually characterized with the key word(s) in the middle of the page, each is in its own textual environment (Sinclair, 1991), which makes the text more accessible and analysis easier. Sinclair (1986) says by sorting the occurrence of particular words, a concordancer can help learners study the patterns in which the given key words are typically used in their own textual context. AntConc 3.2.1 will be the concordancer for concordancing in this paper.

\subsection{What Can These Corpora and Concordances Do to Help Learning and Teaching in General?}

Sinclair (1989) describes a computer as the tool which allows learners to assume mastery of their own learning experience. In other words, corpus and concordance in a learning environment can interject authenticity of text, purpose, 
and activity in the learning process. As Yang (2002) holds the view that the applications of corpus are reflected in the statistics of language frequency, dictionary compilation, study on vocabulary collocation, language teaching and natural language processing. Stevens (1995) concludes that throughout their linguistic performance, learners may become researchers into the language, aiming at discovering its mystery themselves, and thus deducing rules that stem out of the evidence they have before them.

Johns (1991) gives rise to an approach termed "data-driven learning" which describes a procedure where the learner can inductively derive and deductively apply generalizations by categorizing data from corpora. This procedure highlights the effectiveness of inductive learning from multiple examples, so it is also in line with communicative language teaching so as to meet the needs of improving students' communicative competence. Zhen (2005) makes a systematic introduction and illustration of the idea, methods and techniques of corpus based data-driven foreign language learning. He believes that compared with traditional English teaching and learning, data-driven learning is characterized by "autonomous learning", "authentic language input", "self-discovery", and "bottom-up inductive learning".

In general, according to Guy Aston (1998), there are two common ways by which corpus materials are used in promoting language teaching. For one thing, publishers and researchers usually use corpus samples to create language-learning references, syllabuses or some other related tools or materials. For another, the corpus and concordance can be combined with language teaching through typical strategies. In other words, the analysis of the corpus can be incorporated directly into the language teaching and learning environment. This method brings about great opportunities for teachers and language learners to do a lot of things. For instance, to categorize language data extracted from the corpus, and subsequently, try to draw conclusions on the frequently occurring or exceptionally used patterns and features of the target language from the above categorizations.

This paper is more about the latter way of data-driven learning, that is, to apply corpus into actual language teaching and learning environment or the EFL classroom. Even the data used in this method is relatively small, it is definitely authentic.

\section{Results and Discussion}

\subsection{EFL Classroom via Corpus and Concordances}

Teachers play the role of monitors and guide students in their mobile and experienced learning via corpus and concordances. Take the learning of the preposition over in academic texts as an example (task-based learning and the design of the task is essential)

Cognitive linguistics advocates that language is embodied and usage-based, so mobile and experienced learning should be highlighted. This type of learning is to empower students to manage their own learning in a variety of contexts throughout their lifetimes. However, it does not completely replace traditional learning, while it just provides a new way of learning by using new technology. It shows the following advantages: 1 . Make learning more effective and active because learning tasks are built around actively "doing" instead of passively reading and listening; 2 . It is more individualized in light of different kinds of learners' learning styles; 3. When applied to EFL classroom, it is a learner-centered learning with the help of teachers` guidance since teaching contents are presented in such a way that students understand and control the information flow. Teachers change their role from the traditional knowledge initiator to the organizers and instructors of the teaching process. Meanwhile the roles of students move from passive recipients to active explorers and constructors of knowledge.

Teachers need to compile a larger, more authentic corpus and design certain activities or tasks. With the help of corpus or concordance software, sorting a concordance alphabetically according to first right choice helps highlight phrases and other patterns that start with the key word, such as collocations and frequent expressions (Sinclair, 1986).

And then, the teacher should select high frequency collocates. After listing the concordances lines of target words, one can also use a concordance software to search for collocates, which means pick outing those words or phrases which are on a high frequency basis to collocate with the target words. Just as the Chart 2 show: 


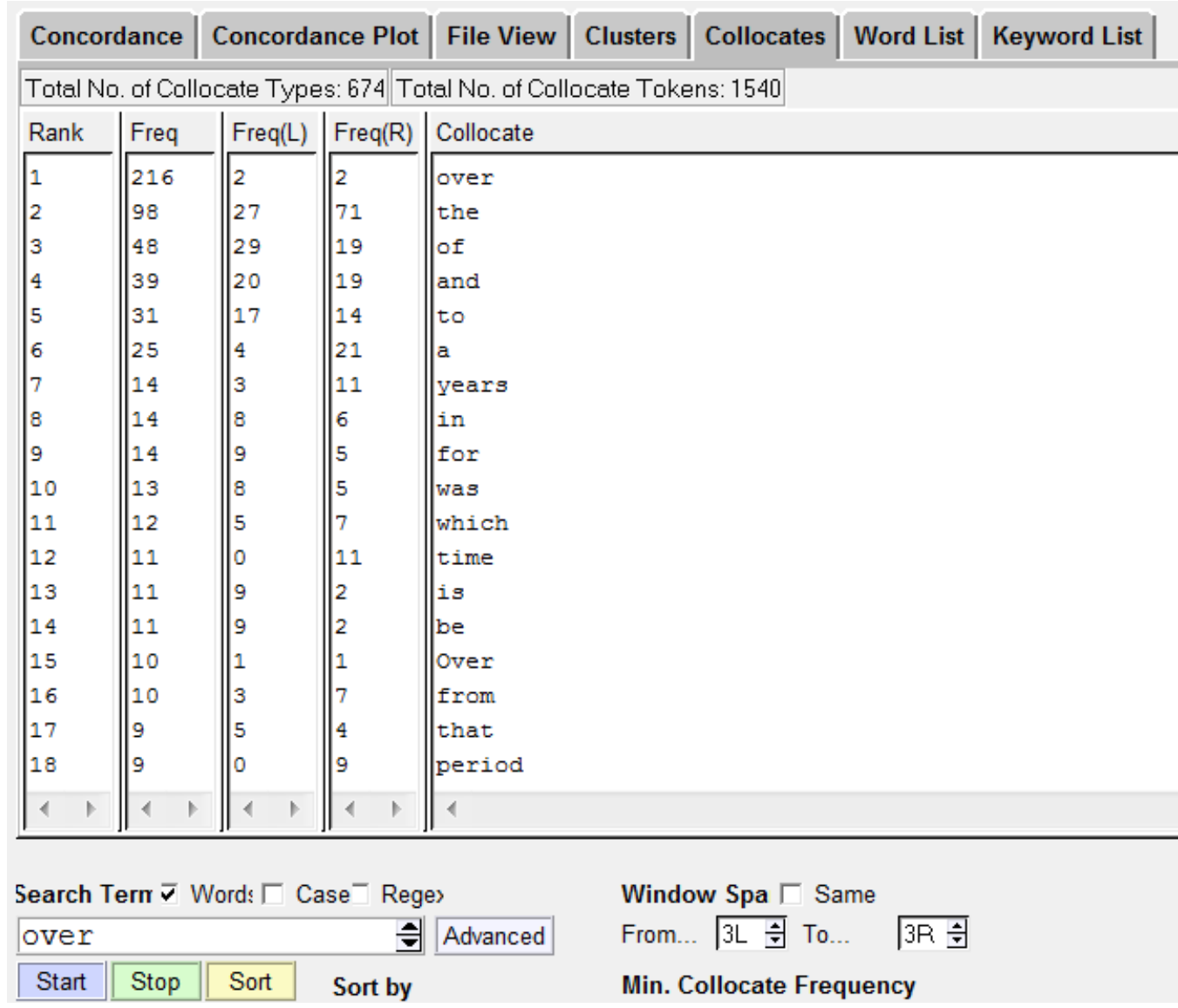

Chart 1 Collocate Frequency of Over in AntConc 3.2.1

Besides, the teacher also can use concordance software to figure out the words clusters of target words in chosen language data, as showed in chart 2: 


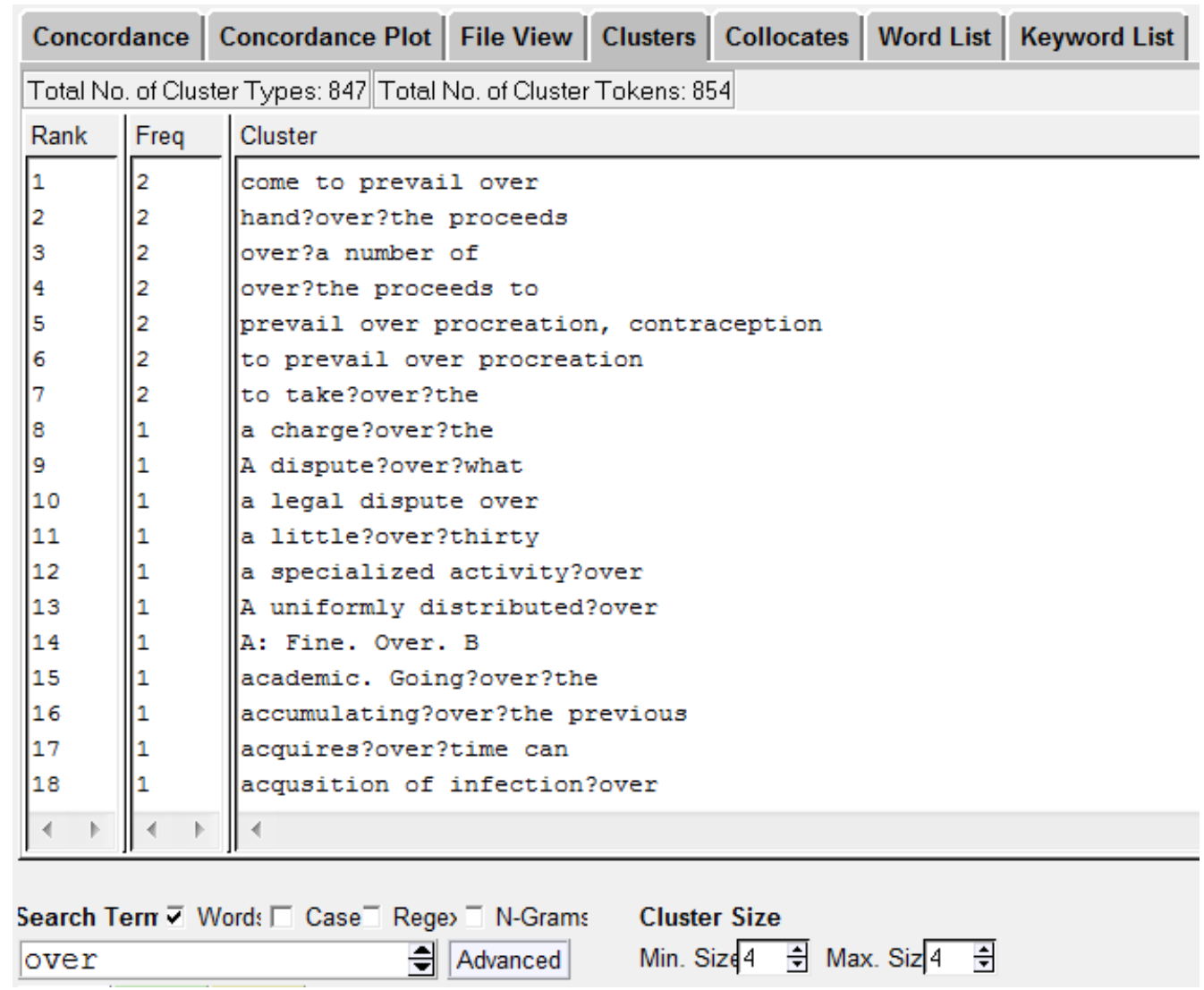

Chart 2. The Clusters of Over in AntConc3.2.1

Next the teacher may begin to design classroom tasks, like giving various question types according to the objectives of the tasks. Commonly applied questions include blank filling with collocates, word matching, or word recognition.

For example, to apply blank filling task in classroom, by which the teacher can tell how much successful their work on such kind of tasks is through looking at their outcome. The teacher shall gain feedback from students who have finished the carefully-designed activities.

During all these procedures, there are several points for recommendations. Firstly, even collecting data from corpora is kind of time-consuming, the teacher is expected to carry out collaborative work during extracting and selecting data for target words. Secondly, for the sake of choosing proper teaching data, teachers may turn to cooperative colleagues' critiques and assistance who can provide teachers with the necessary feedback. And then teachers should continue collecting and accumulating data for teaching, by which they can improve a capacity for teaching with the help of corpora and concordancer.

Here comes the Corpus-based vocabulary teaching and learning procedures for teacher to follow. Students are going to learn the meanings of the polysemy by observing and analyzing the concordance lines, such as the collocation, structure or some other with the help of language data.

\section{Teacher`s Task Design:}

Before class: 1.select target words and language data from corpus

2.process the data in concordance software

During the class: teacher should guide students to finish the tasks

3.present the concordance lines(data)

4. put forward questions or activities;

5. After students` answering: conclude and assess students` tasks \& results

Here is the brief introduction to this designing steps:

In the teaching process, firstly, the teacher should choose the target words according to the teaching aim and needs, and then extract proper amount of language data from the corpora. Secondly, the teacher processes the target word in the 
concordance software like AntConc for producing the concordance lines. And then the teacher also need to further process the concordance lines by removing those which are too difficult or complicated for the students to understand by reference to students` learning abilities. Thirdly, the teacher ought to display the processed concordance lines on the projector or screen during the class for the students to observe, process and analyze. Fourthly, the teacher should give some hints for the students to think over and analyze by asking questions or presenting activities, Of course in this process, the students will be allowed to discuss with their partners. Finally, after students observing, processing, analyzing, independent thinking, discussion and conclusion, the teacher is supposed to summarize the class.

\subsection{Student-Self Learning via Corpus and Concordances}

Task-based self-learning and teachers must give a certain task with clear requirement and instructions; Mobile and experienced self-learning. Take the learning of the word over in academic texts as an example (teach students the knowledge about the word over in advance; what is and how many semantic items over comprises etc..

Laura Gavioli (2001) in her study puts forward a kind of learning style in which students are supposed to be researchers by themselves, and she further discusses some important issues in the analysis of corpus data, like emphasizing on observing and generalizing recurrent patterns and their typical contexts of use during language learning process, and the learner should induce their own generalizations as a researcher. It emphasizes the student-centered exploratory learning mode, which fundamentally changes the traditional top-down teaching mode to a student-centered learning mode.

First, students are encouraged to think bigger than the word itself-always to look for two or three word expressions as far as noun, adjective, verb and adverb are concerned and then highlight the crucial role of noun. The fact that nouns tend to be the focus of information in a text, means that nouns are the most suitable headwords for collocation and usage search.

Search strategies themselves are relatively simple and straight forward. Teachers can encourage students to follow the steps. And more practice will make the strategies routine and automatic.

As students work through more and more exercises on the usage of a word like over, they become more and more sensitive as to whether two words are possible collocates or not. Such sensitivity is particularly important for their independent language learning.

Here comes the student-centered learning procedures under the teacher's guidance for students to follow during EFL classroom by applying corpus and concordance. Students are going to learn the meanings of the polysemy by observing and analyzing the concordance lines, such as the collocation, structure or some other with the help of language data.

Students` tasks:

Before class: (prepare for Corpus website and Concordance software) Download and install the concordance software;

During class: under teacher`s guidance to carry out those activities

1. Observe and analyze the concordance lines;

2. process the concordance lines (using a concordance software);

3. discuss and generalize(teachers can give hints or ask questions and students can discuss with their partners);

4. conclude their findings;

5. discuss and reflect.

After class: redo teachers' tasks and finish some assignments linked to the target words(using the Corpus and Concordancer)

\subsection{Teacher-Guided \& Students-Centered EFL Classroom via Corpus and Concordance Software}

According to what discussed above, this paper attempts to propose a possible model for EFL teaching and learning classroom as shown in figure 2 below. 


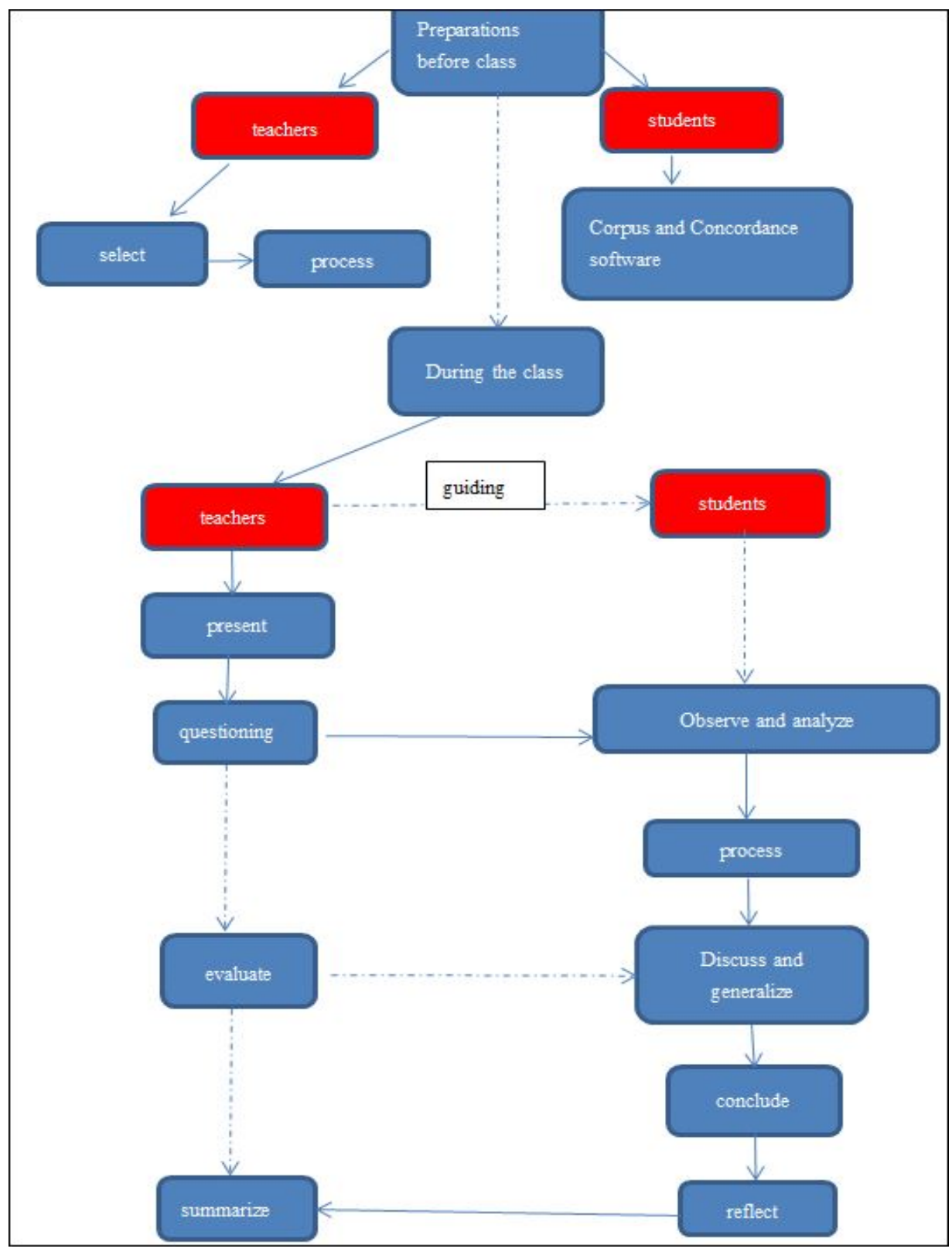

Figure 2. Teaching Procedures Via Corpus and Concordance Software

The red brackets in figure 1 represent the classroom participants; the blue brackets represent the steps about the procedures; the full lines refer to the routine direction; the dotted lines indicate the implied relationship between two steps.

These teaching procedures contain two main processing lines, and each is centered on and executed by a core role, i. e. the classroom participants (the teacher and students). On the left of the figure, it is the teacher-guided classroom procedures. Even the teaching strategies discussed in this paper emphasize students' independent learning via technologies like corpus and concordance software, the role of teachers in EFL classroom cannot be replaced or neglected. Teachers should be a guide to give students directions and suggestions by regulating class processes, asking critical and inspiring questions, manufacturing problem-solving activities, etc., which are absolutely integral to the whole procedure.

While the other processing line is about the center role of students in EFL classroom applying corpus and concordance, students are treated as explorers, executors, researchers and main participants by self-centered learning in this strategy. In other words, they are supposed to be responsible for their self-learning. However, in order to activate these procedures, teacher-and-student interaction and collaboration is needed. 
Specifically in this method, teachers and students can carry out the following actions via corpus and concordance. Before class begins, the teacher should

(1) carefully select target words and language data about the target words from corpus;

(2) process the data in concordance software to watch the characteristics of target word's usage, meanings, collocation, structural feature and so on. And students ought to

(3) prepare for available corpus and concordance software by downloading and installing the concordance software.

During class, the teacher provides guidance for students to finish the tasks all the way. The teacher should firstly

(4) present the concordance lines (data) in front of students on the screen, and after a moment

(5) put forward central questions or give problem-solving activities. Then students ought to carry out the activities under teacher's guidance.

(6) Firstly observe and analyze the concordance lines; then

(7) process the concordance lines by using concordance software;

(8) next discuss the questions with their partners and try to generalize the rules and features, through which teachers can give hints or ask questions and students can discuss with their partners;

(9) and then students conclude their findings, during this process teacher should evaluate students' answers;

(10) after finishing all the tasks, students can discuss and reflect on their learning. Finally

(11) after students' answering, the teacher should give a summary by concluding and assessing students' tasks and results.

After class, for better learning efficiency, students ought to redo teachers' tasks and finish some assignments linked to the target words by using the Corpus and Concordance software.

\section{Summary}

This paper develops a practical teaching \& learning strategy for EFL classroom by applying corpus and concordance, and this strategy should be activated through flexible cooperation and interaction between the teacher and students. A Teacher-Guided \& Students-Centered EFL Classroom model Via Corpus and Concordance Software is presented accordingly in the end aiming at fostering teaching and learning via corpus and concordances, and empower teachers with the capabilities for this kind of teaching and learning.

\section{Acknowledgements}

Many thanks to our dear colleagues who provide generously great help during the research in some aspects such as language refinement and proof reading for the paper. And the article is sponsored by 2015 Jiangsu University Philosophy and social sciences research project (2015SJD032); 2017 Nanjing University of Aeronautics and Astronautics Central University basic research expenses special funding (NR2017028); 2017 Nanjing University of Aeronautics and Astronautics undergraduate education and teaching reform research project (2017JG1213Z); 2017 Nanjing University of Aeronautics and Astronautics undergraduate education and teaching reform research project (2017JG1228Y).

\section{References}

Aston, G. (1998). What corpora for ESP? In M. Pavesi \& M. Bernini (Ed.), L'apprendimento Linguistico nell'Università: Le Lingue Speciali (pp.205-226). Roma: Bulzoni.

Bachman, L. F. (1990). Fundamental Consideration in Language Testing. Oxford: Oxford University Press.

Flowerdew, J. (1996). Concordancing in language learning. In P. Martha (Ed.), The Power of CALL (pp. 97-113). Houston: Athelstan.

Gavioli, L. (2001). The learner as researcher: introducing corpus concordancing in the classroom. In G. Aston (Ed.), Learning with corpora (pp.108-137). Houston: Athelstan.

Hymes, D. H. (1972). On communicative competence. In J. B. Pride \& J. Holmes (Ed.), Sociolinguistics (pp. 269-293). London: Penguin.

Johns, T. (1991). Should you be persuaded: two examples of data driven learning. ELR Journal (New Series), 4, 1-16. http://wordsmithtools.com/wordsmith/corpus_linguistics_links/Tim\%20Johns\%20and\%20DDL.pdf 
Lotherington, H., \& Ronda, N. (2014). 2B or not 2B? from pencil to multimodal programming: new frontiers in communicative competencies. In J. P. Guikema \& L. Williams (Ed.), Digital literacies in foreign and second language education (pp.9-28). San Marcos, TX: CALICO Monograph.

Sinclair, J. M. (1986). Basic computer processing of long texts. In G. Leech \& C. N. Candin (Ed.), Computers in English Language Teaching and Research(pp. 185-203). London: Longman.

Sinclair, J. M. (1991). Corpus, concordance, collocation. London, NY: Oxford University Press.

Stevens, V. (1995). Concordancing with Language Learners : Why? When ? What ?. CAELL Journal (Computer Assisted English Language Learning), 6(2), 2-10. http://www.eisu2.bham.ac.uk/johnstf/stevens.htm

Yang, H. Z. (2002). An introduction to corpus linguistics. Shanghai, NY: Shanghai Foreign Language Education Press.

Zhen, F. C. (2005). Corpus-based data-driven foreign language learning: ideas, methods and techniques. Foreign Language World, 4, 19-27. https://wenku.baidu.com/view/7b543a680b1c59eef8c7b480.html

\section{Copyrights}

Copyright for this article is retained by the author(s), with first publication rights granted to the journal.

This is an open-access article distributed under the terms and conditions of the Creative Commons Attribution license which permits unrestricted use, distribution, and reproduction in any medium, provided the original work is properly cited. 